\title{
Equation of state and high-pressure phase behaviour of $\mathrm{SrCO}_{3}$
}

\author{
Nicole Biedermann ${ }^{1,2}$, Elena Bykova ${ }^{3}$, Wolfgang Morgenroth ${ }^{2,4}$, Ilias Efthimiopoulos ${ }^{5}$, Jan Mueller ${ }^{5}$, \\ Georg Spiekermann $^{2,6}$, Konstantin Glazyrin ${ }^{7}$, Anna Pakhomova ${ }^{7}$, Karen Appel ${ }^{1}$, and Max Wilke ${ }^{2}$ \\ ${ }^{1}$ European XFEL, Schenefeld, Germany \\ ${ }^{2}$ Institute for Geosciences, University of Potsdam, Potsdam-Golm, Germany \\ ${ }^{3}$ Geophysical Laboratory, Carnegie Institution of Washington, Washington, D.C., USA \\ ${ }^{4}$ c/o European Synchrotron Radiation Facility ESRF, Grenoble, France \\ ${ }^{5}$ GFZ German Research Center for Geosciences, Potsdam, Germany \\ ${ }^{6}$ Institute of Geochemistry and Petrology, ETH Zürich, Zürich, Switzerland \\ ${ }^{7}$ Deutsches Elektronen Synchroton DESY, Hamburg, Germany
}

Correspondence: Nicole Biedermann (nicole.biedermann@xfel.eu)

Received: 6 December 2019 - Revised: 10 October 2020 - Accepted: 16 October 2020 - Published: 3 November 2020

\begin{abstract}
The high-pressure phase transition of strontianite $\left(\mathrm{SrCO}_{3}\right)$ was investigated at ambient temperature by means of powder and single-crystal X-ray diffraction. The samples were compressed in a diamond anvil cell to a maximum pressure of $49 \mathrm{GPa}$. Structure refinements confirm the existence of $\mathrm{SrCO}_{3}$ in the low pressure aragonite-type phase Pmcn (62) up to about $26 \mathrm{GPa}$. Above this pressure, $\mathrm{SrCO}_{3}$ transforms into a high-pressure phase with post-aragonite crystal structure Pmmn (59). Fitting the volume extracted from the compression data to the third-order Birch-Murnaghan equation of state for the low-pressure phase of $\mathrm{SrCO}_{3}$ yields $K_{0}=62.7(6) \mathrm{GPa}$ and $K_{0}^{\prime}=3.2(1)$, and for the high-pressure phase this yields $K_{0}=103(10) \mathrm{GPa}$ and $K_{0}^{\prime}=2.3(6)$. The unit cell parameters change non-uniformly, with the $c$ axis being 4 times more compressible than the $a$ and $b$ axes. Our results unequivocally show the existence of a Pmmn structure in $\mathrm{SrCO}_{3}$ above $26 \mathrm{GPa}$ and provide important structural parameters for this phase.
\end{abstract}

\section{Introduction}

Carbonates play a key role in the chemistry and dynamics of our planet. They are directly connected to the $\mathrm{CO}_{2}$ budget of our atmosphere and have a great impact on the deep carbon cycle (Li et al., 2019; McCammon et al., 2020). Moreover, it is believed that more than $90 \%$ of the planet's carbon content is stored in the Earth's deep interior (Javoy, 1997; Dasgupta and Hirschmann, 2010; Kelemen and Manning, 2015). Indirect evidence for the presence of a deep carbon cycle is given by the existence of carbonatite melts causing metasomatism in the upper mantle (Litasov et al., 2013), by $\mathrm{CO}_{2}$ in peridotitic and eclogitic systems with implications for deep melting of subducting slabs (Ghosh et al., 2009; Litasov, 2011; Thomson et al., 2016), by mantle minerals (e.g. clinopyroxene, olivine, garnet) hosting carbon-bearing inclusions (Korsakov and Hermann, 2006; Shcheka et al., 2006), and the formation of diamonds. Several studies performed under the conditions of the Earth's mantle showed that carbon is incorporated in carbonates, which are stable phases at such conditions in equilibrium with other mineral phases (Isshiki et al., 2004; Merlini et al., 2012a,b; Boulard et al., 2015; Bayarjargal et al., 2018; Santos et al., 2019). Findings of carbonate inclusions in diamonds from the upper mantle and transition zone further substantiate the existence of carbonates in the deep Earth (Sobolev et al., 1998; Wirth et al., 2009; Brenker et al., 2007; Kaminsky et al., 2009).

The most abundant carbonates entering the subduction zone are $\mathrm{Ca}, \mathrm{Mg}$, and $\mathrm{Fe}$ carbonates. At the pressuretemperature (PT) conditions expected for subduction zones and the Earth's mantle, carbonates undergo pressure- and temperature-induced structural changes: $\mathrm{CaCO}_{3}$, for instance, undergoes several phase transitions, some of them be- 
coming more relevant to Earth's mantle conditions (Martinez et al., 1996; Santillán and Williams, 2004; Ono et al., 2005a; Oganov et al., 2006; Bayarjargal et al., 2018); other studies have shown the stability and phase transition of dolomite (Zucchini et al., 2017; Solomatova and Asimow, 2017; Efthimiopoulos et al., 2017), which is thought to be the main carbonate phase in subducting slabs. Regarding $\mathrm{CaCO}_{3}$, numerous studies on the phase behaviour of aragonite-type $\mathrm{CaCO}_{3}$ at high pressure reported a phase transition from orthorhombic aragonite (space group Pmcn) into monoclinic $\mathrm{CaCO}_{3}$-VII at around $30 \mathrm{GPa}$ and into post-aragonite structure Pmmn at around $40 \mathrm{GPa}$ (Gavryushkin et al., 2017; Bayarjargal et al., 2018).

Meanwhile, strontianite $\left(\mathrm{SrCO}_{3}-\mathrm{I}\right)$, which is isostructural to aragonite at room pressure and room temperature conditions and very common in natural carbonates, is considered to have similar phase transitions but is at a lower pressure compared to aragonite due to the larger ionic radius of $\mathrm{Sr}^{2+}$ $(1.31 \AA)$ in comparison with $\mathrm{Ca}^{2+}(1.18 \AA)$ (Shannon, 1976). Recent findings on mineral inclusions in transition zone diamonds showed significant amounts of strontium (Brenker et al., 2007; Kaminsky, 2012), which motivated our investigations of $\mathrm{SrCO}_{3}$ as a possible stable phase in the deep Earth.

Whilst most of the physical properties of $\mathrm{SrCO}_{3}$ are well known at ambient conditions (Villiers, 1971; Antao and Hassan, 2009; Nguyen-Thanh et al., 2016; Biedermann et al., 2017b), they have rarely been measured by powder X-ray diffraction at high pressure (Ono et al., 2005b; Wang et al., 2015), with some of them being based on density functional theory (DFT) calculations (Biedermann et al., 2017a; Efthimiopoulos et al., 2019). However, up to now, no singlecrystal X-ray diffraction data were measured on $\mathrm{SrCO}_{3}$, thus making it difficult to analyse structural changes at the conditions of the Earth's mantle. At ambient pressure, $\mathrm{SrCO}_{3}$ has an aragonite-type crystal structure with space group Pmcn (62). This crystal structure consists of planar trigonal $\left[\mathrm{CO}_{3}\right]^{2-}$ oxyanions parallel to (001). The cations (e.g. $\mathrm{Sr}^{2+}$ ) are surrounded by six $\mathrm{CO}_{3}^{2-}$ ions in a trigonal prismatic arrangement parallel to the $c$ axis (see Fig. 8a), whereas the carbonate groups are octahedrally surrounded by six cations. The higher coordination number of the cation in the aragonite-group minerals correlates with a larger ionic radius (e.g. $\mathrm{Sr}^{2+}, \mathrm{Ba}^{2+}, \mathrm{Pb}^{2+}$ ) compared to the calcite-group minerals, where the cation is only coordinated six-fold by the oxygen atoms.

A few studies on the pressure-induced phase transitions in $\mathrm{SrCO}_{3}$ have been performed (Lin and Liu, 1997; Arapan and Ahuja, 2010; Wang et al., 2015; Biedermann et al., 2017a; Efthimiopoulos et al., 2019). They partially disagree regarding both the stability field and the structure of the highpressure phases. Lin and Liu (1997) suggested a phase transition of $\mathrm{SrCO}_{3}$ to post-aragonite between 32 and $35 \mathrm{GPa}$ by Raman spectroscopy and proposed a space group setting of $P 2{ }_{1} 22$ for this phase. In comparison, Ono et al. (2005b) observed a post-aragonite phase by powder X-ray diffraction of $\mathrm{SrCO}_{3}$ already at $14.5 \mathrm{GPa}$ and at $40 \mathrm{GPa}$ for $\mathrm{CaCO}_{3}$ (Ono et al., 2005a). In a later study, Ono (2007) could show that the post-aragonite modification in $\mathrm{BaCO}_{3}$ has to be the same post-aragonite structure as $\mathrm{CaCO}_{3}$ and $\mathrm{SrCO}_{3}$ and had to be described in space group setting Pmmn. More recently, Wang et al. (2015) reported a possible high-pressureinduced transition at room temperature of $\mathrm{SrCO}_{3}$ from Pmcn to $P 22_{1} 2_{1} 2$ between 22.2 and $26.9 \mathrm{GPa}$ and of $\mathrm{BaCO}_{3}$ from Pmcn to Pmmn between 9.8 and $11.2 \mathrm{GPa}$. A similar pressure range for a transition to the post-aragonite phase in $\mathrm{SrCO}_{3}$ was proposed by Biedermann et al. (2017a) using experimental and computational Raman spectroscopy. Later on, the boundary of this phase transition was extended to hightemperature conditions using mid-infrared absorbance and Raman spectroscopy in combination with DFT-based calculations (Efthimiopoulos et al., 2019).

The variety of experimental conditions and techniques in the cited studies leads to results that are difficult to compare and sometimes even contradictory. To clarify these controversies we investigated the structure of pure $\mathrm{SrCO}_{3}$ up to $49 \mathrm{GPa}$ at ambient temperature by powder and single-crystal $\mathrm{X}$-ray diffraction. This method allows us to precisely determine the crystal structure and to finally resolve the disagreement concerning the correct space group symmetry for the post-aragonite phase.

\section{Methods}

\subsection{Synthesis of sample material}

For powder X-ray diffraction experiments, we used commercial $\mathrm{SrCO}_{3}$ powder from Sigma Aldrich Chemical Company (99.995\% purity). The single crystals of pure $\mathrm{SrCO}_{3}$ strontianite were grown in a Walker-type multi-anvil apparatus at $4 \mathrm{GPa}$ and $1273 \mathrm{~K}$ for $24 \mathrm{~h}$ using the same $\mathrm{SrCO}_{3}$ powder as a starting material. The same synthesis has been used in previous studies (Biedermann et al., 2017a,b). The chemical composition of the synthesized sample was determined using a JEOL Hyperprobe JXA-8500F with a field emission cathode at the GFZ Potsdam. Analysis was conducted with an acceleration voltage of $15 \mathrm{kV}$, a $10 \mathrm{nA}$ beam current, and $\mathrm{a}<10 \mu \mathrm{m}$ focused beam size. As reference-standard materials we used dolomite for $\mathrm{CaO}$ and strontianite for $\mathrm{SrO}$. The chemical analysis indicated a concentration for $\mathrm{Ca}^{2+}$ below the detection limit of $130 \mathrm{ppm}$ (see the Supplement for electron microprobe analysis). In addition, the morphology and chemical composition of the single crystals were studied with scanning electron microscopy. Most of the synthesized single crystals of $\mathrm{SrCO}_{3}$ were twinned, which is very common for aragonite-type carbonates, as they exhibit pseudohexagonal morphologies with a mirror plane (110) as a twin plane (Bragg, 1924). 


\subsection{High-pressure X-ray diffraction experiments}

\subsubsection{Powder X-ray diffraction experiments}

For high-pressure X-ray diffraction studies, $\mathrm{SrCO}_{3}$ powder was pressurized to $49 \mathrm{GPa}$ in a membrane-driven Mao-Belltype diamond anvil cell (Mao and Hemley, 1997) equipped with $400 \mu \mathrm{m}$ culets. Drilled pre-indented rhenium gaskets with a hole diameter of $200 \mu \mathrm{m}$ served as sample chambers. The pressure-transmitting medium (PTM) neon and a ruby sphere were loaded in addition to the sample. The pressure in the cell was measured with an online HR-2000 spectrometer (Ocean Optics) using the $\mathrm{R}_{1}$-line fluorescence band shift of ruby described by Mao et al. (1986) directly before and after each measurement, where the average is used as the experimental pressure. In addition, the equation of state of neon was used for additional pressure calibration (Hemley et al., 1989). The powder and single-crystal XRD experiments were carried out at beamline P02.2 at PETRA III, DESY (Hamburg) (Liermann et al., 2015). The X-ray wavelength was $\lambda=0.2906 \AA$, and the beam size was $2 \times 2 \mu \mathrm{m}^{2}$ at full width at half maximum (FWHM). The calibration of the wavelength and the sample-to-detector distance was performed using standard $\mathrm{CeO}_{2}$ powder. For data collection, we used a fast flat panel detector XRD1621 from Perkin Elmer (2048 pixels $\times 2048$ pixels with $200 \times 200 \mu \mathrm{m}^{2}$ pixel size). The two-dimensional X-ray images were integrated using the Fit2D programme (Hammersley, 2016). Refinements of the powder X-ray diffraction data were performed using the GSAS and EXPGUI software packages (Larson and Von Dreele, 2004).

\subsubsection{Single-crystal X-ray diffraction experiments}

In the case of high-pressure single crystal X-ray diffraction experiments, a small crystal of $\mathrm{SrCO}_{3}(25-30 \mu \mathrm{m}$ in diameter and $10 \mu \mathrm{m}$ thickness $)$, a piece of tungsten $(\sim 10 \mu \mathrm{m}$ in diameter) and a ruby sphere $(\sim 10 \mu \mathrm{m}$ in diameter $)$ were placed into a $150 \mu \mathrm{m}$ wide cylindrical chamber drilled in a pre-indented rhenium gasket. We used the same type of membrane-driven diamond anvil cells as in the case of powder samples but using diamonds with a smaller culet size of $300 \mu \mathrm{m}$. Again, neon was loaded into the cell as a pressure-transmitting medium. The single crystal was pressurized up to pressures of $26.3 \mathrm{GPa}$. A picture of the single crystal loaded into the cell and compressed to $25.9 \mathrm{GPa}$ is shown in Fig. 1 .

The intensities of the reflections for the $\mathrm{SrCO}_{3}$ single crystal were integrated in steps of $0.5^{\circ}$ over the entire opening angle of the cell of $54^{\circ}$. At each pressure point, additional X-ray diffraction wide images (from -27 to $+27^{\circ}$ in the rotation axis) were collected to confirm the data quality. The instrument model of the experimental geometry (sample-to-detector distance, the detector's origin, offsets of the goniometer angles, and rotation of the X-ray beam and the detector around the in-

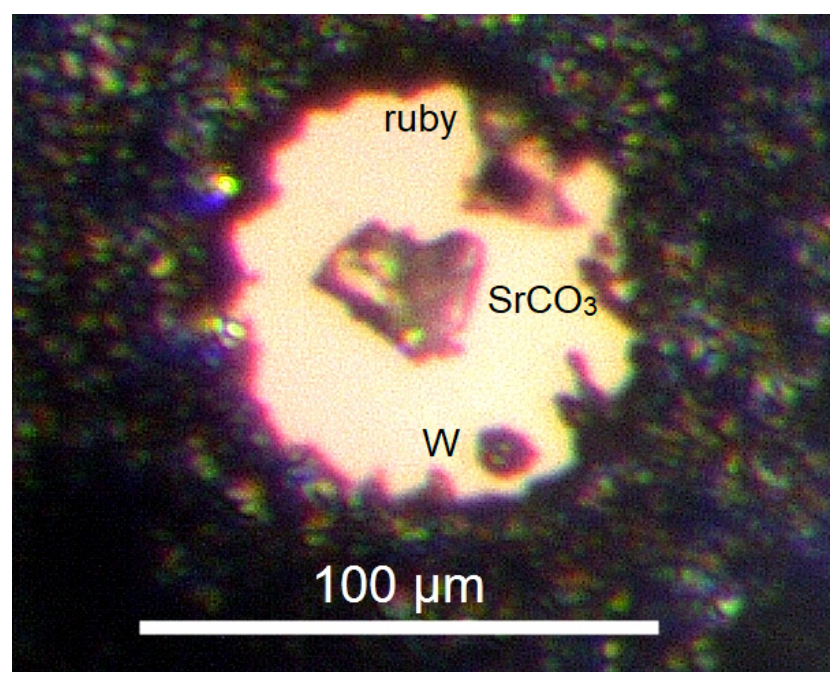

Figure 1. Diamond anvil cell at 25.9 GPa loaded with a single crystal of $\mathrm{SrCO}_{3}$, with neon as a pressure-transmitting medium, a ruby sphere, and a piece of tungsten. The beam size was $2 \mu \mathrm{m} \times 2 \mu \mathrm{m}$ FWHM.

Table 1. Observed $d$ spacings of the post-aragonite phase $\mathrm{SrCO}_{3}$-II at $26.3 \mathrm{GPa}$ and room temperature in comparison with those from previous work (Ono et al., 2005b).

\begin{tabular}{rrr}
\hline hkl & $\begin{array}{r}\text { This study } \\
d_{\text {obs }}[\AA] \\
(26.3 \mathrm{GPa})\end{array}$ & $\begin{array}{r}\text { Ono et al. }(2005 \mathrm{~b}) \\
d_{\text {obs }}[\AA] \\
(14.5 \mathrm{GPa})\end{array}$ \\
\hline 001 & 4.2320 & 4.3106 \\
110 & 3.3436 & 3.4197 \\
011 & 3.2136 & 3.2750 \\
101 & 3.0966 & 3.1644 \\
111 & 2.6236 & 2.6803 \\
020 & 2.4695 & 2.5210 \\
200 & 2.2715 & 2.3260 \\
021 & 2.1329 & 2.0477 \\
121 & 1.9307 & 1.9720 \\
102 & 1.9181 & 1.9545 \\
211 & 1.5849 & 1.8964 \\
\hline
\end{tabular}

strument axis) was calibrated against an orthoenstatite reference crystal: $\left(\mathrm{Mg}_{1.93} \mathrm{Fe}_{0.06}\right)\left(\mathrm{Si}_{1.93} \mathrm{Al}_{0.06}\right) \mathrm{O}_{6}, P b c a ; a=$ 18.2391(3) $\AA \quad b=8.8117(2) \AA ; c=5.18320(10) \AA)$. The processing of XRD data (the unit cell determination and integration of the reflection intensities) was performed using CrysAlis PRO software (Rigaku Oxford Diffraction, 2019). Indexing of the unit cell was carried out on about 30 reflections manually selected in the reciprocal space viewer (Ewald explorer implemented in CrysAlis PRO software). The reflections were selected in order to determine a 3D lattice in the reciprocal space. The identified unit cell parameters were then refined on the whole set of reflections at the end of the integration. 

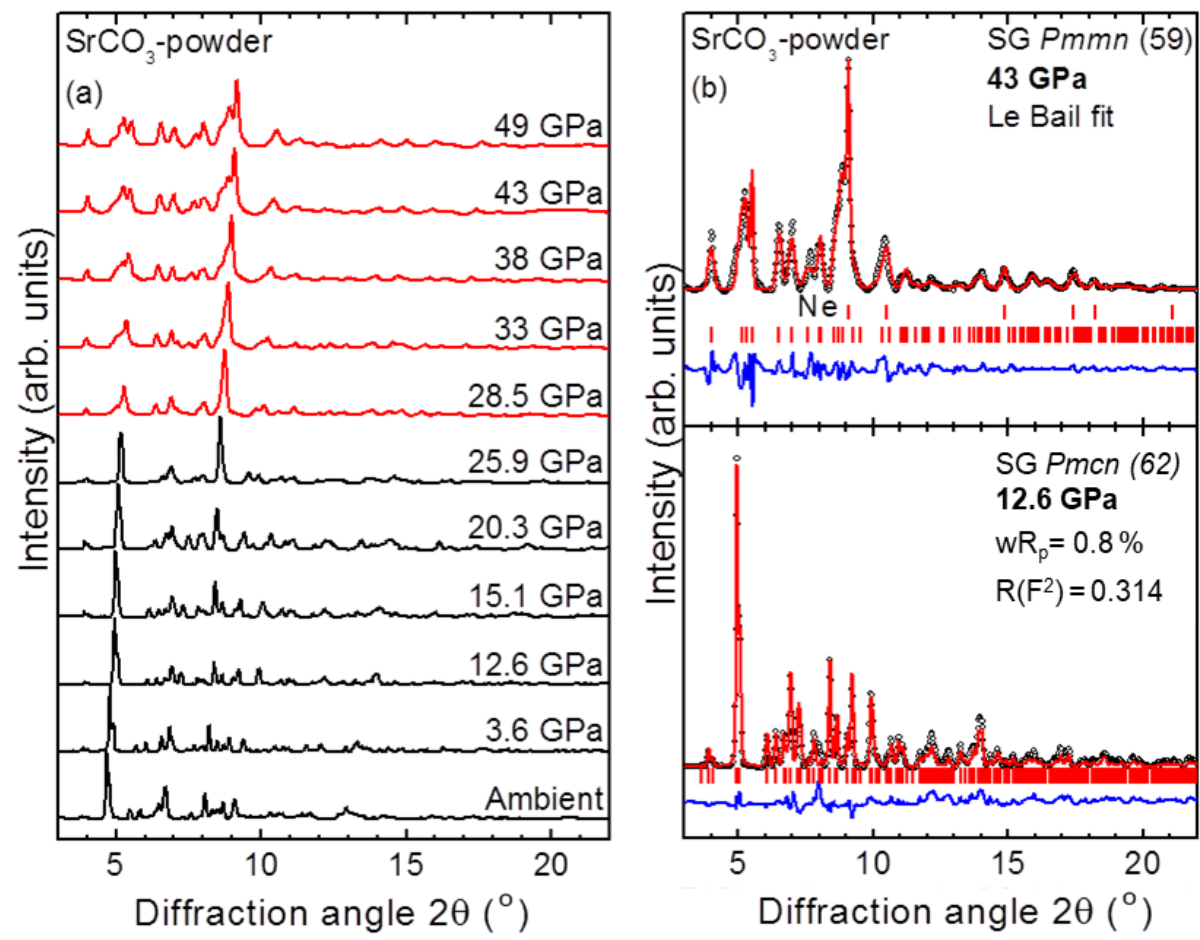

Figure 2. (a) Powder XRD patterns of $\mathrm{SrCO}_{3}$ at various pressures $(T=300 \mathrm{~K} ; \lambda=0.2906 \AA)$. The different phases are indicated by black $\left(\mathrm{SrCO}_{3}-\mathrm{I}\right)$ and red $\left(\mathrm{SrCO}_{3}-\mathrm{II}\right)$ colours. (b) Refined XRD patterns for the aragonite-type $\mathrm{SrCO}_{3}$-I phase (12.6 GPa, Rietveld, bottom) and for $\mathrm{SrCO}_{3}$-II (43 GPa, Le Bail, top). Dots correspond to the measured spectra and the solid red lines represent the best refinements. The difference curves between the measured and the refined patterns are depicted as well (blue curves). Vertical ticks mark the Bragg peak positions.

Table 2. Pressure dependence of lattice parameters of $\mathrm{SrCO}_{3}$ at room temperature derived from powder X-ray diffraction.

\begin{tabular}{lclll}
\hline$P[\mathrm{GPa}]$ & $a[\AA]$ & $b[\AA]$ & $c[\AA]$ & $V\left[\AA^{3}\right]$ \\
\hline \multicolumn{2}{l}{$\mathrm{SrCO}_{3}$-I in $P m c n$} & & & \\
\hline 0.0001 & $5.126(1)$ & $8.472(2)$ & $6.061(1)$ & $263.21(15)$ \\
$3.6(1)$ & $5.057(1)$ & $8.358(2)$ & $5.840(1)$ & $246.81(15)$ \\
$12.6(2)$ & $4.978(1)$ & $8.182(2)$ & $5.419(1)$ & $220.73(15)$ \\
$15.1(2)$ & $4.957(1)$ & $8.121(2)$ & $5.337(1)$ & $216.94(15)$ \\
$20.3(2)$ & $4.929(1)$ & $8.017(2)$ & $5.186(1)$ & $209.85(15)$ \\
$25.9(3)$ & $4.892(1)$ & $7.878(2)$ & $5.037(1)$ & $202.32(15)$ \\
\hline \multicolumn{2}{l}{$\mathrm{SrCO}_{3}$-II in $P m m n$} & & & \\
\hline $28.5(3)$ & $4.521(1)$ & $4.918(1)$ & $4.219(1)$ & $93.79(8)$ \\
$33(1)$ & $4.459(1)$ & $4.879(1)$ & $4.194(1)$ & $91.25(8)$ \\
$38(1)$ & $4.393(1)$ & $4.845(1)$ & $4.171(1)$ & $88.79(8)$ \\
$43(1.5)$ & $4.325(1)$ & $4.811(1)$ & $4.151(1)$ & $86.39(8)$ \\
$49(2)$ & $4.244(1)$ & $4.782(1)$ & $4.127(1)$ & $83.75(8)$ \\
\hline
\end{tabular}

Errors in parentheses are a single standard deviation.

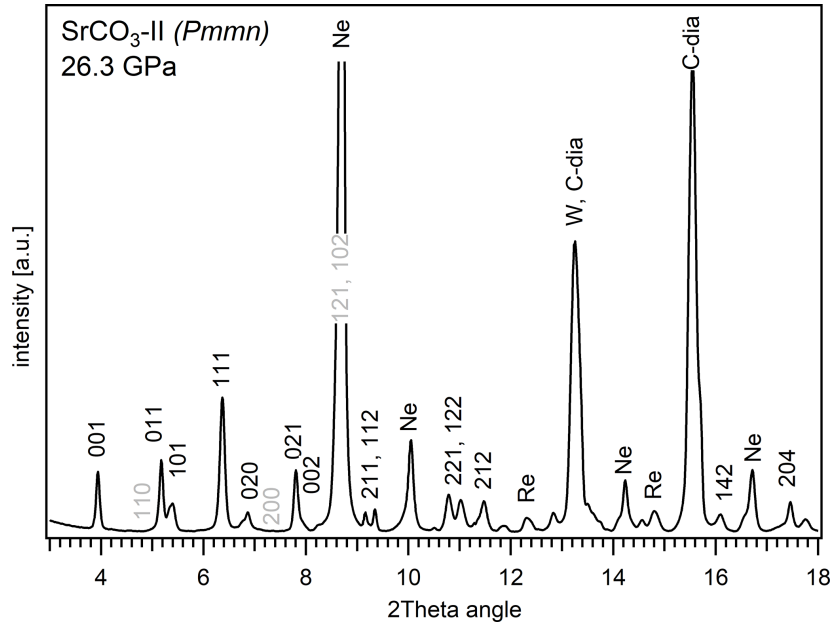

Figure 3. A representative XRD pattern of post-aragonite $\mathrm{SrCO}_{3}$-II obtained from single-crystal data at $26.3 \mathrm{GPa}$ derived from continuous rotation around one axis from -27 to $+27^{\circ}$ (wide scan image). Reflections corresponding to $\mathrm{SrCO}_{3}$-II that are absent, less intense, or overlaid are marked in grey. 
The selected grain of $\mathrm{SrCO}_{3}$ was a non-merohedral twin with following transformation:

$$
\left(\begin{array}{ccc}
-0.46 & -0.54 & 0 \\
1.46 & -0.46 & 0 \\
0 & 0 & 1
\end{array}\right) .
$$

The transformation corresponds to two oriented grains rotated by about $118^{\circ}$ around the common $c$ axis. Since the degree of overlap was small (less than $3 \%$ of all reflections), no twin integration was applied for the $\mathrm{SrCO}_{3}$-I phase data, and only the most intense grain (e.g. larger volume) was used for extraction of the reflection intensities. Overlapping $00 l$ reflections were missing in the data set due to the orientation of the crystal in the diamond anvil cell (DAC) and its restricted opening angle. However, after the phase transition above $26 \mathrm{GPa}$ we observed three twin domains related to a three-fold rotation along the $a$ axis in $\mathrm{SrCO}_{3}$-II. Due to a high degree of overlap between reflections (about 10\%), we applied simultaneous twin integration; however, further structure solution and refinement was performed using the data collected from the most intense twin component. Empirical absorption correction was applied using spherical harmonics, implemented in the SCALE3 ABSPACK scaling algorithm, which is included in the CrysAlis PRO software. The crystal structures of aragonite-type $\mathrm{SrCO}_{3}$-I and post-aragonite $\mathrm{SrCO}_{3}$-II were determined by the dual space method using SHELXT (Sheldrick, 2015) software. After the structure solution most of the atoms were found and the remaining were located from a series of difference Fourier maps. The crystal structures were refined against $F^{2}$ on all data by full-matrix least squares with the SHELXL (Sheldrick, 2015) software. The amount of the collected data allowed us to refine the structures in anisotropic approximation. Nevertheless, there is a pronounced elongation of anisotropic displacement parameters in $\mathrm{SrCO}_{3}$-II along the [100] direction, due to threefold twinning about the $a$ axis. Details of crystal structure refinements of $\mathrm{SrCO}_{3}-\mathrm{I}$ and $\mathrm{SrCO}_{3}$-II are given in Table 3 . The X-ray crystallographic coordinates have been deposited at the Inorganic Crystal Structure Database (ICSD) under deposition no. CSD1944794. This data can be obtained from CCDC's and FIZ Karlsruhe's free service for viewing and retrieving structures (http://www.ccdc.cam.ac.uk/structures/, last access: 28 October 2020).

\section{Results and discussion}

\subsection{Phase transition of $\mathrm{SrCO}_{3}$ during compression}

Powder XRD patterns in the $2 \theta$ range $3-22^{\circ}$ were collected upon compression up to $49(2) \mathrm{GPa}$ and are presented in Fig. 2. No other peaks except those of the sample and the pressure transmitting medium neon $(\mathrm{Ne})$ were observed. Peaks corresponding to the sample at ambient conditions were well indexed to the low-pressure aragonite structure Pmcn with the lattice parameters $a=5.126(1) \AA$, $b=8.472(2) \AA$, and $c=6.061(1) \AA$ and are in agreement with the literature (Wang et al., 2015; Villiers, 1971; Arapan and Ahuja, 2010; Antao and Hassan, 2009). As shown in Fig. 2, reflections of $\mathrm{SrCO}_{3}$ shift to higher angles with increasing pressure and no structural transformation occurred until 25.9(3) GPa. A Rietveld refinement for the low-pressure aragonite-type $\mathrm{SrCO}_{3}$-I phase up to a pressure of $15.1(2) \mathrm{GPa}$ was used to calculate the lattice and structural parameters, including interatomic distances. Above $15 \mathrm{GPa}$, the broadening of the peaks does not allow reliable refinement of the structure; hence the method of Le Bail fitting was applied in order to derive lattice parameters from powder-XRD measurements between 15 and $49 \mathrm{GPa}$.

Some reflections of $\mathrm{SrCO}_{3}$-I disappear, and new peaks appear at 28.5(3) GPa that could not be indexed using the metric of $\mathrm{SrCO}_{3}$-I described in space group Pmcn. These new peaks increase in intensity at higher pressures and indicate that $\mathrm{SrCO}_{3}$ has transformed into a post-aragonite phase. Our observations are in good agreement with powder X-ray diffraction studies from Wang et al. (2015) where a phase transition in $\mathrm{SrCO}_{3}$ was observed between 22.2 and $26.9 \mathrm{GPa}$. In contrast, Ono et al. (2005b) proposed the presence of a post-aragonite phase in $\mathrm{SrCO}_{3}$ already at $14.5 \mathrm{GPa}$ and at high temperature, which was also indexed with the metric of $\mathrm{SrCO}_{3}$-II described in space group Pmmn. For $\mathrm{CaCO}_{3}$, a phase transformation into post-aragonite was observed at $40 \mathrm{GPa}$ (Ono et al., 2005a) and for $\mathrm{BaCO}_{3}$ at $10 \mathrm{GPa}$ (Ono, 2007; Townsend et al., 2013). The pressure for a phase transition in $\mathrm{SrCO}_{3}$ determined here lies in between these values and complies with the pressure-homologue rule according to which isostructural compounds often exhibit similar phase transitions but at lower pressures with increasing ionic radius (Ringwood, 1975).

Single-crystal X-ray diffraction experiments were performed from 0 to $26.3 \mathrm{GPa}$. In agreement with our results from powder X-ray diffraction, reflections of the single crystal can be unambiguously indexed with the same aragonitetype orthorhombic cell Pmcn between 0 and about $21 \mathrm{GPa}$. Results taken at $26.3 \mathrm{GPa}$ clearly indicate that $\mathrm{SrCO}_{3}$ has fully transformed into post-aragonite phase with space group Pmmn, which is the stable phase of $\mathrm{SrCO}_{3}$ at this higher pressure. The XRD pattern derived from a wide scan of the single crystal at this pressure is shown in Fig. 3. Additional peaks are indexed for rhenium, tungsten and the pressure transmitting medium neon. Fitted $d$ spacings from this study at 26.3 GPa are given in Table 1 and are in good agreement with previous results from Ono et al. (2005b) at $14.5 \mathrm{GPa}$.

A comparison between the low-pressure phase and the post-aragonite phase is shown in Fig. 4. One can see that the $a, b$, and $c$ axes in $\mathrm{SrCO}_{3}$-I (Pmcn) correspond to the $b, c$, and $a$ axes in $\mathrm{SrCO}_{3}$-II (Pmmn). The phase transition from $\mathrm{SrCO}_{3}$-I (Pmcn) to $\mathrm{SrCO}_{3}$-II (Pmmn) is a first-order phase transition (Ono et al., 2005a) and is described by a shift of half of $\mathrm{Sr}^{2+}$ cations and $\mathrm{CO}_{3}^{2-}$ anions along the [100] direc- 
Table 3. Details of single-crystal structure refinements of $\mathrm{SrCO}_{3}-\mathrm{I}$ and $\mathrm{SrCO}_{3}$-II between 0.5 and $26.3 \mathrm{GPa}$.

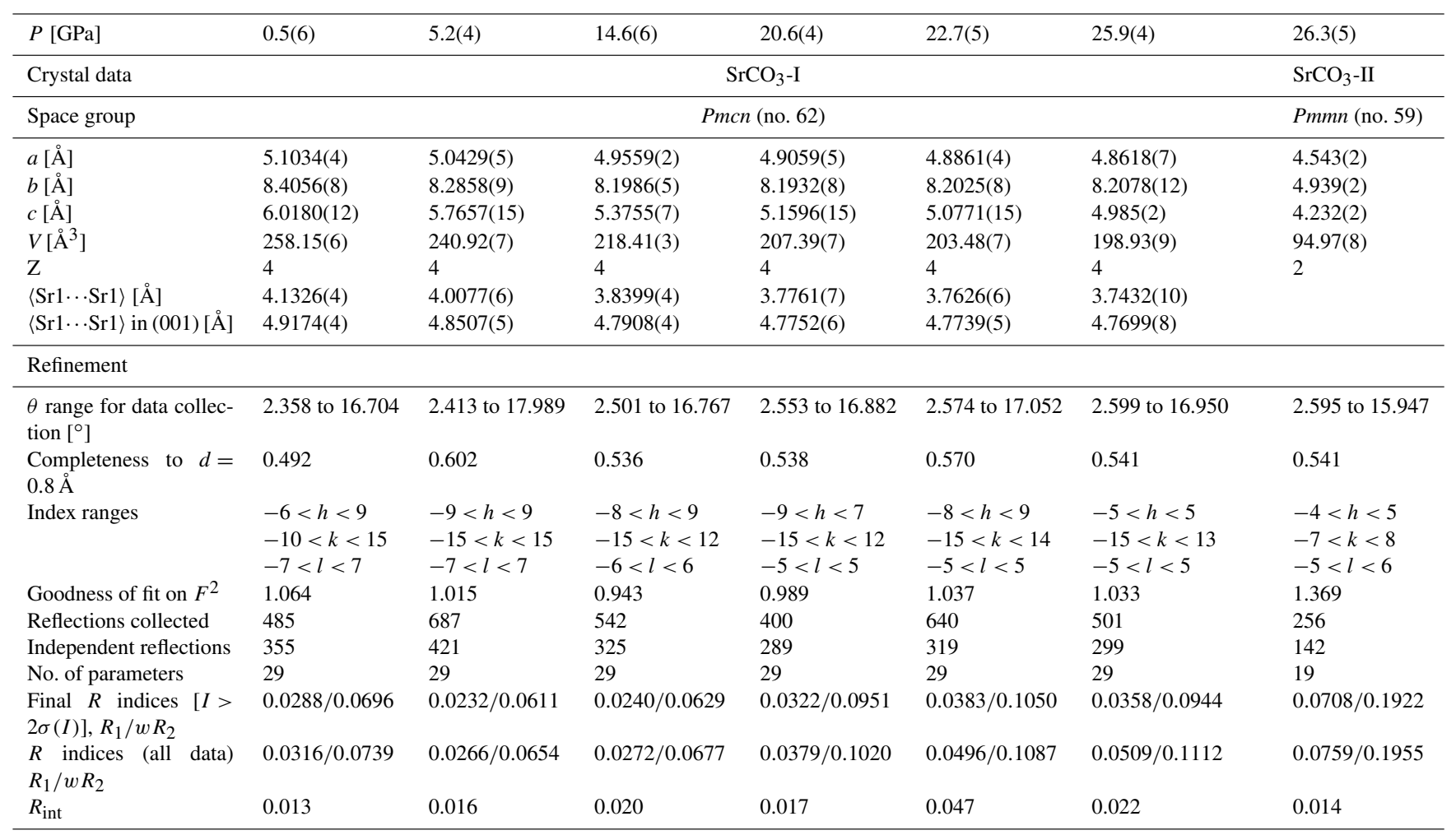

(a)

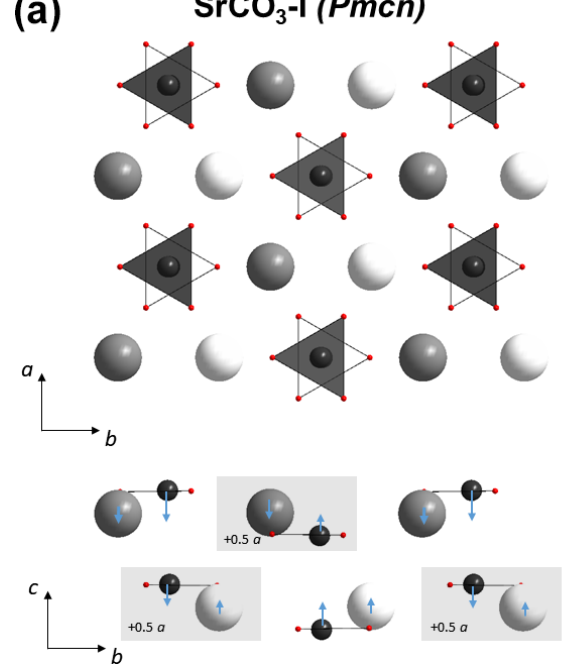

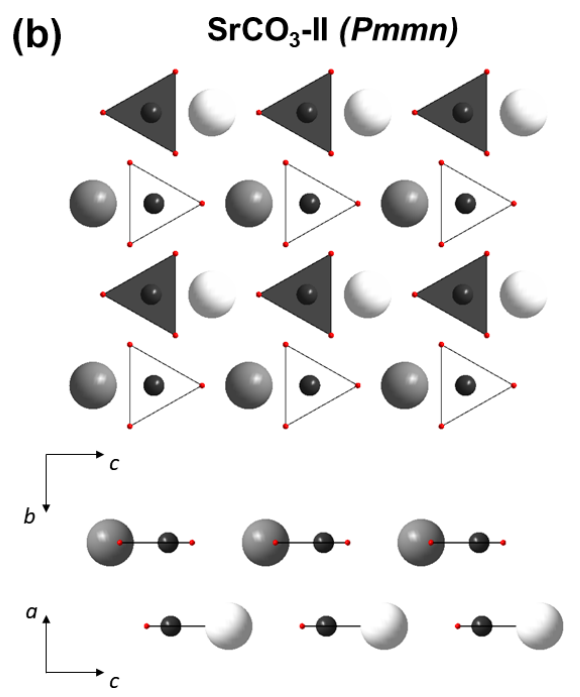

Figure 4. Crystal structures of $\mathrm{SrCO}_{3}-\mathrm{I}$ (a) and $\mathrm{SrCO}_{3}$-II (b). Axis $a, b$, and $c$ in $\mathrm{SrCO}_{3}-\mathrm{I}$ (Pmcn) correspond to $b, c$ and $a$ axis in $\mathrm{SrCO}$ - $\mathrm{II}$ (Pmmn). Small-sized red spheres correspond to oxygen atoms, black spheres are carbon, $\mathrm{CO}_{3}^{2-}$ are additionally highlighted as white and dark grey triangles, with different positions along the $c$ axis in $\mathrm{SrCO}_{3}$-I and along the $a$ axis in $\mathrm{SrCO}_{3}$-II. White and dark grey spheres are $\mathrm{Sr}^{2+}$. During the phase transition from aragonite to post-aragonite half of $\mathrm{Sr}^{2+}$ and $\mathrm{CO}_{3}^{2-}$ ions highlighted by grey rectangles shift by $0.5[100]$ and then the ions line up in the (001) plane (the directions of displacements are shown by small blue arrows). 


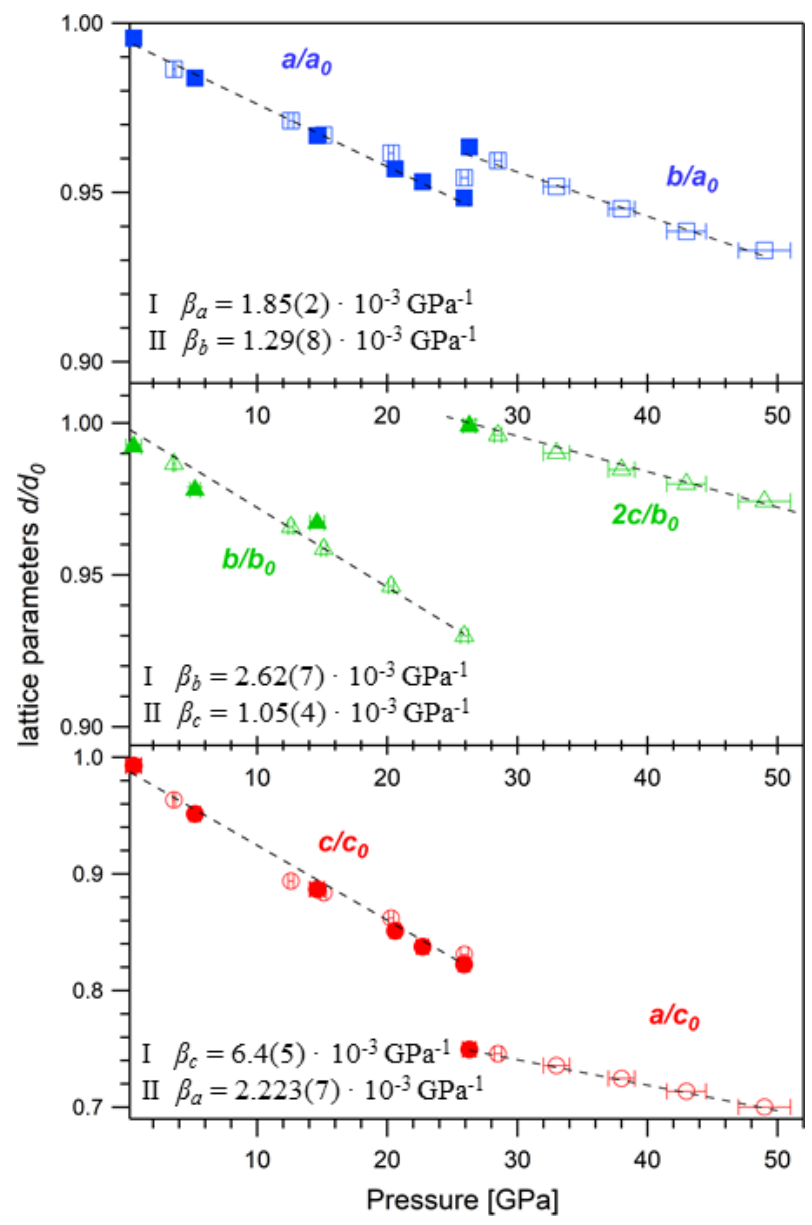

Figure 5. Compressibility of the unit cell parameters $\beta_{a}, \beta_{b}$, and $\beta_{c}$ for $\mathrm{SrCO}_{3}$-I and $\mathrm{SrCO}_{3}$-II. Open symbols are data derived from powder samples, and solid symbols are from single-crystal X-ray diffraction. Note that the $a, b$, and $c$ axes in $\mathrm{SrCO}_{3}-\mathrm{I}$ (Pmcn) correspond to the $b, c$, and $a$ axes in $\mathrm{SrCO}_{3}$-II (Pmmn). The lattice parameters at ambient conditions are $a_{0}=5.126(1) \AA, b_{0}=$ 8.472(2) $\AA$, and $c_{0}=6.061(1) \AA$.

tion. At the same time, a shift by half of the translation of all $\mathrm{Sr}^{2+}$ cations and $\mathrm{CO}_{3}^{2-}$ anions accompanied with a small displacement along [001] occurs such that the cations and anions line up in one plane parallel to (001). These shifts result in more dense packing of cations and anions and in the increase of the $\mathrm{Sr}^{2+}$ coordination number from 9 to 12 .

\subsection{Compressibility of $\mathrm{SrCO}_{3}-\mathrm{I}$ and $\mathrm{SrCO}_{3}-\mathrm{II}$}

The refined unit cell parameters for the low-pressure phase strontianite $\left(\mathrm{SrCO}_{3}-\mathrm{I}\right)$ and for the high-pressure phase $\mathrm{SrCO}_{3}$-II obtained at different pressures are listed in Tables 2 and 3 . The evolution of the lattice parameters with pressure is given in Fig. 5. Upon compression from 0.5 to $26 \mathrm{GPa}$, the axes of $\mathrm{SrCO}_{3}$-I change anisotropically with the highest compressibility found in the direction of the $c$ axis, which is perpendicular to the carbonate groups. This anisotropic

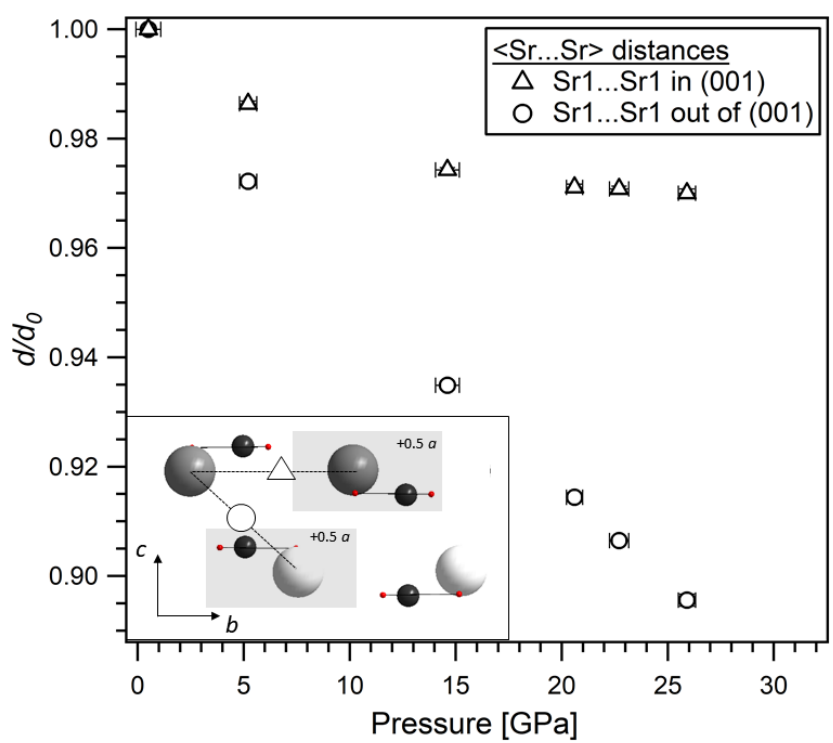

Figure 6. Evolution with pressure of the $\langle\mathrm{Sr} \cdots \mathrm{Sr}\rangle$ distances in the (001) plane (distance between two grey $\mathrm{Sr}$ spheres) and out of the (001) plane (distance between grey and white $\mathrm{Sr}$ spheres) in $\mathrm{SrCO}_{3}-$ I derived from single-crystal X-ray diffraction data. A schematic drawing of the crystal structure of $\mathrm{SrCO}_{3}-\mathrm{I}$ in the (100) plane is given as an inset.

compression scheme is typical for aragonite-type carbonates (Townsend et al., 2013; Zhang et al., 2013) and reflects the incompressibility of the $\mathrm{CO}_{3}$ groups in the (001) plane compared to the $\mathrm{SrO}_{9}$ polyhedra. The determined lattice parameters for $\mathrm{SrCO}_{3}$-I in this study exhibit quasi-linear pressure dependence with no obvious discontinuities. A linear fit of the given $a / a_{0}, b / b_{0}$, and $c / c_{0}$ values against pressure yields linear compressibilities of $\beta_{a}, \beta_{b}$, and $\beta_{c}$ with $1.85(2) \times 10^{-3}$, $2.62(7) \times 10^{-3}$, and $6.4(5) \times 10^{-3} \mathrm{GPa}^{-1}$, respectively, and agrees well with data from Wang et al. (2015). Variations of the $\mathrm{Sr} \cdots \mathrm{Sr}$ distances in $\mathrm{SrCO}_{3}$-I upon compression further substantiate an anisotropic compression behaviour, indicating anomalous contraction along the $c$ axis (Fig. 6). Across phase transition at about $26 \mathrm{GPa}$, the length of the $c$ axis ( $\hat{=} a$ in $\mathrm{SrCO}_{3}$-II) sharply decreases by $\sim 10 \%$, whereas the $b$ axis $\left(\hat{=} c\right.$ in $\mathrm{SrCO}_{3}$-II) increases. The lattice parameters of $\mathrm{SrCO}_{3}$-II further decrease with pressure, albeit at lower rates, indicating that the structure of $\mathrm{SrCO}_{3}-\mathrm{II}$ is less compressible than $\mathrm{SrCO}_{3}$-I. The linear compressibilities of the high-pressure phase are found to be 2.223(7) $\times 10^{-3} \mathrm{GPa}^{-1}$ for the $a$ axis, $1.29(8) \times 10^{-3} \mathrm{GPa}^{-1}$ for the $b$ axis, and $1.05(4) \times 10^{-3} \mathrm{GPa}^{-1}$ for the $c$ axis.

The pressure dependence of the molar volume for $\mathrm{SrCO}_{3}-\mathrm{I}$ and $\mathrm{SrCO}_{3}-\mathrm{II}$ is shown in Fig. 7a. A plot of the Eulerian strain against the normalized pressure (f-F plot) (Fig. 7b) indicates that a third-order Birch-Murnaghan equation of state is necessary to fit the pressure-volume (P-V) data of $\mathrm{SrCO}_{3}$, which 

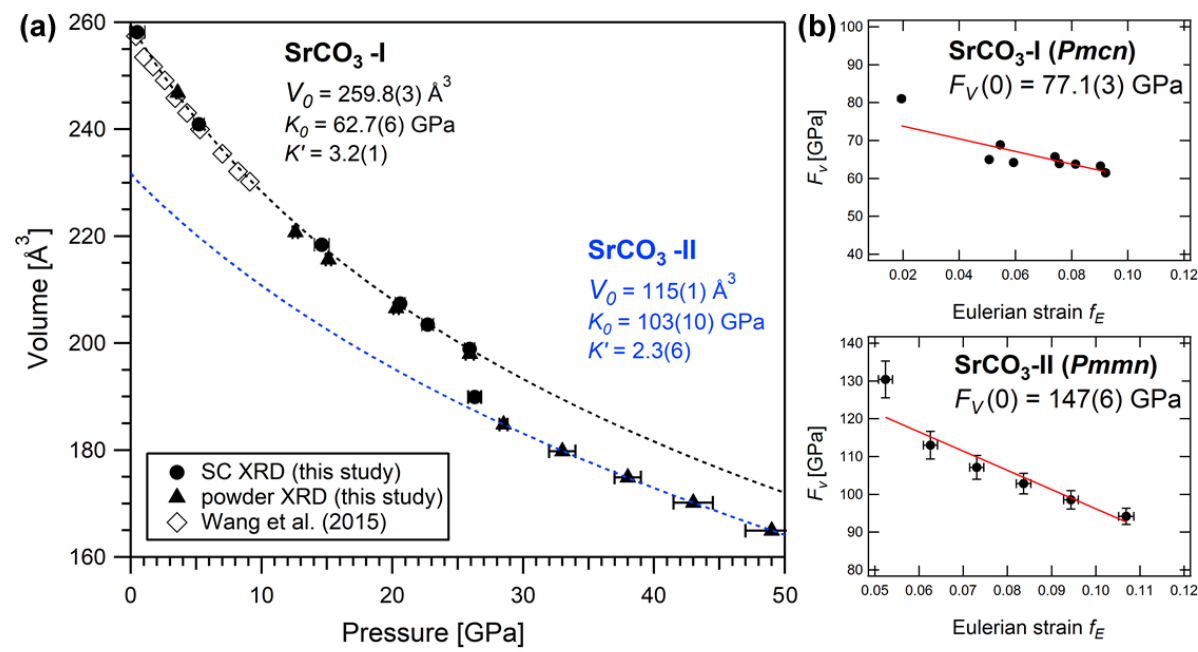

Figure 7. (a) Isothermal compression of the molar volume plotted together with the best fit following the Birch-Murnaghan equation of state for $\mathrm{SrCO}_{3}-\mathrm{I}$ (dashed black line) and $\mathrm{SrCO}_{3}$-II (dashed blue line). Open symbols are data from Wang et al. (2015) (with methanol and ethanol as PTM), and solid symbols are from this study. Note that for $\mathrm{SrCO}_{3}$-II the depicted data points show the doubled values of the unit cell volume. (b) Normalized pressure $\left(F_{V}\right)$ as a function of the Eulerian strain $(f)$ for $\mathrm{SrCO}_{3}$-I and $\mathrm{SrCO}_{3}$-II, respectively. The solid red lines are the weighted linear fits to the data at $P>3.6 \mathrm{GPa}$.

(a)

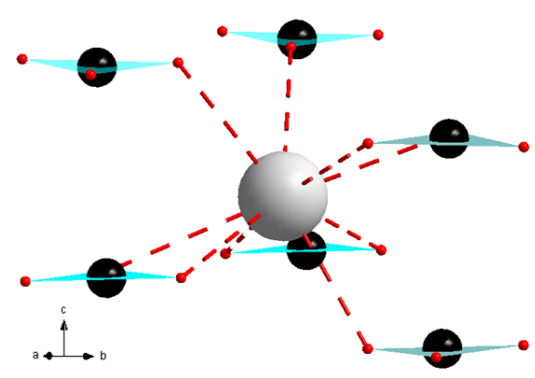

(b)

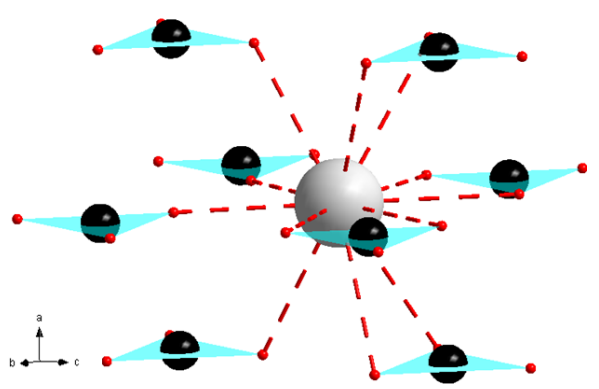

Figure 8. A fragment of $\mathrm{SrCO}_{3}-\mathrm{I}$ (a) and $\mathrm{SrCO}_{3}$-II (b) crystal structure at ambient pressure and at $26.3 \mathrm{GPa}$, respectively, showing $\mathrm{Sr}^{2+}$ ions (light grey sphere) surrounded by six $\mathrm{CO}_{3}^{2-}$ anions in the aragonite structure, whereas $\mathrm{Sr}^{2+}$ ions in the post-aragonite structure are surrounded by eight triangular $\mathrm{CO}_{3}^{2-}$ anions (C: dark grey spheres; $\mathrm{O}$ : red spheres).

is expressed as follows (Birch, 1947; Angel et al., 2014):

$P(\mathrm{GPa})=3 K_{0} f_{\mathrm{E}}\left[\left(1+2 f_{\mathrm{E}}\right)^{\frac{5}{2}}\left(1+\frac{3}{2}\left(K^{\prime}-4\right) f_{\mathrm{E}}\right)\right]$,

with $f_{\mathrm{E}}$ as the Eulerian strain given by

$f_{\mathrm{E}}=\frac{1}{2}\left[\left(V_{0} / V\right)^{\frac{2}{3}}-1\right]$,

and where $V_{0}, K_{0}$, and $K^{\prime}$ are the (molar) volume, the isothermal bulk modulus, and its pressure derivative at room pressure, respectively. The programme EosFit7c (Angel et al., 2014) was used to fit the data. For the low-pressure phase strontianite $\left(\mathrm{SrCO}_{3}-\mathrm{I}\right)$, the following EoS parameters were calculated: $V_{0}=259.8(3) \AA^{3}, K_{0}=62.7(6) \mathrm{GPa}$, and $K_{0}^{\prime}=3.2(1)$. Values for $K_{0}$ are in good agreement with previous studies on strontianite (Wang et al., 2015; Biedermann et al., 2017b). The fit result for the high-pressure phase $\mathrm{SrCO}_{3}$-II yields $V_{0}=115(1) \AA^{3}, K_{0}=103(10) \mathrm{GPa}$ and $K_{0}^{\prime}=2.3(6)$, respectively. As indicated in Table 4, these values are between the values for $\mathrm{BaCO}_{3}$-II, with $K_{0}=$ 84(4) $\mathrm{GPa}(\mathrm{Ono}, 2007)$, and for post-aragonite $\mathrm{CaCO}_{3}$, with 127(14) GPa (Ono et al., 2005a), thus confirming a dependency on the cation radius.

\subsection{Crystal structure of post-aragonite $\mathrm{SrCO}_{3}$-II}

A detailed refinement of the high-pressure phase was carried out on single crystal X-ray diffraction data at $26.3 \mathrm{GPa}$. We were able to refine the structure in the anisotropic approximation. Fractional atomic coordinates and anisotropic displacement parameters are shown in Table 5. At this pressure, the post-aragonite phase of $\mathrm{SrCO}_{3}$ crystallizes in an orthorhombic unit cell with space group Pmmn (no. 59, origin choice 2) and with the following unit cell parameters: $a=4.543(2) \AA$, 
Table 4. Comparison of the literature data for aragonite-type (Pmcn) and post-aragonite $\left(P m m n\right.$ or $\left.P 2{ }_{1} 2{ }_{1} 2\right)$ carbonates at ambient conditions.

\begin{tabular}{|c|c|c|c|c|}
\hline & $V_{0}\left[\AA^{3}\right]$ & $K_{0}[\mathrm{GPa}]$ & $K_{T 0}^{\prime}$ & References \\
\hline \multicolumn{5}{|c|}{ Aragonite-type carbonates } \\
\hline \multirow{3}{*}{$\mathrm{CaCO}_{3}$} & $227.5(8)$ & $65(4)$ & 4 (fixed) & Martinez et al. (1996) \\
\hline & $227.2(10)$ & $67.1(63)$ & $4.7(8)$ & Ono et al. (2005a) \\
\hline & $227.2(10)$ & $73.1(22)$ & 4 (fixed) & Ono et al. (2005a) \\
\hline \multirow{3}{*}{$\mathrm{SrCO}_{3}-\mathrm{I}$} & $258.4(3)$ & $62(1)$ & 4 (fixed) & Wang et al. (2015) \\
\hline & $258.4(1)$ & $64(4)$ & & Biedermann et al. (2017b) \\
\hline & $259.8(3)$ & $62.7(6)$ & $3.2(1)$ & This work \\
\hline \multirow[t]{4}{*}{$\mathrm{BaCO}_{3}$} & $303.8(1)$ & $50.4(9)$ & $1.9(4)$ & Holl et al. (2000) \\
\hline & $304.1(3)$ & $44.3(8)$ & 4 (fixed) & Holl et al. (2000) \\
\hline & 319.3 & 47.2 & 2.4 & Ono et al. (2008) \\
\hline & $304.8(3)$ & $48(1)$ & 4 (fixed) & Wang et al. (2015) \\
\hline \multicolumn{5}{|c|}{ post-aragonite carbonates } \\
\hline \multirow[t]{3}{*}{$\mathrm{CaCO}_{3}$ Post-aragonite } & $98(2)$ & $127(14)$ & 4 (fixed) & Ono et al. (2005a) \\
\hline & $102(3)$ & $90(13)$ & 4.94 & Oganov et al. (2006) \\
\hline & 109.74 & $42(7)$ & $7(1)$ & Oganov et al. (2006) \\
\hline \multirow[t]{2}{*}{$\mathrm{SrCO}_{3}$-II } & $115(1)$ & $103(10)$ & $2.3(6)$ & This work \\
\hline & $111(2)$ & 101(16) & 4 (fixed) & Ono et al. (2005b) \\
\hline \multirow[t]{2}{*}{$\mathrm{BaCO}_{3}$ post-aragonite } & $129.0(7)$ & $84(4)$ & 4 (fixed) & Ono (2007) \\
\hline & $128.1(5)$ & $88(2)$ & $4.8(3)$ & Townsend et al. (2013) \\
\hline
\end{tabular}

Table 5. Atomic coordinates and anisotropic displacement parameters $U_{i j}\left[\AA^{2}\right]$ for post-aragonite $\mathrm{SrCO}_{3}$-II at $26.3 \mathrm{GPa}$ (space group Pmmn).

\begin{tabular}{llrrrrrrrrr}
\hline Site & $\begin{array}{l}\text { Wyckoff } \\
\text { position }\end{array}$ & $x$ & $y$ & $z$ & $U_{11}$ & $U_{22}$ & $U_{33}$ & $U_{23}$ & $U_{13}$ & $U_{12}$ \\
& & & & & & & & & \\
$\mathrm{Sr}$ & $2 b$ & 0.25 & -0.25 & $0.6186(4)$ & $0.036(2)$ & $0.0096(8)$ & $0.0152(10)$ & 0 & 0 & 0 \\
$\mathrm{C}$ & $2 a$ & 0.25 & 0.25 & $0.991(4)$ & $0.04(2)$ & $0.010(5)$ & $0.007(8)$ & 0 & 0 & 0 \\
$\mathrm{O} 1$ & $2 a$ & 0.25 & 0.25 & $0.682(3)$ & $0.029(12)$ & $0.005(4)$ & $0.011(6)$ & 0 & 0 & 0 \\
$\mathrm{O} 2$ & $4 e$ & 0.25 & $0.025(2)$ & $0.146(2)$ & $0.026(11)$ & $0.012(3)$ & $0.009(4)$ & $0.000(2)$ & 0 & 0 \\
\hline
\end{tabular}

$b=4.939(2) \AA, c=4.232(2) \AA$, and $V=94.97(8) \AA^{3}$. The atomic arrangement in post-aragonite $\mathrm{SrCO}_{3}$-II adopts the structure type of the orthorhombic high-pressure form of $\mathrm{RbNO}_{3}-\mathrm{V}$ (Kalliomäki and Meisalo, 1979). The $\mathrm{Sr}$ ion is located on a Wyckoff position $2 b, \mathrm{C}$ is on a $2 a$ position, and $\mathrm{O} 1$ and $\mathrm{O} 2$ atoms occupy $2 a$ and $4 e$ positions, respectively (Table 5). The same crystal structure was already proposed for high-pressure modifications of $\mathrm{CaCO}_{3}$ (Ono et al., 2005a) and for $\mathrm{BaCO}_{3}$ (Ono, 2007; Townsend et al., 2013). However, there are also XRD data suggesting a trigonal symmetry for the post-aragonite phase in $\mathrm{CaCO}_{3}$ (Santillán and Williams, 2004) and in $\mathrm{BaCO}_{3}$ (Holl et al., 2000). When adapting the trigonal symmetry reported by Holl et al. (2000) some diffraction peaks of the high-pressure phase of $\mathrm{SrCO}_{3}$ could not be indexed. We conclude that for $\mathrm{SrCO}_{3}$ only an orthorhombic description of the crystal structure for the postaragonite phase is possible.
The Pmcn to Pmmn transition of $\mathrm{SrCO}_{3}$ is characterized by an increase of the coordination of $\mathrm{Sr}^{2+}$ from 9 to 12 . The relative change in density across this transition is about $5 \%$. In the post-aragonite phase the $\mathrm{Sr}$ to $\mathrm{O}$ interatomic distances vary from $2.418(10)$ to $2.718(6) \AA$. Six oxygen atoms with shorter distances $(2.418(10), 2.4842(19)$, and $2.613(10) \AA)$ are located on a plane intersecting Sr, parallel to the $b c$ plane. Three oxygen atoms are located below the plane, and three atoms are located above it. $\mathrm{C}$ to $\mathrm{O}$ distances in the highpressure phase of $\mathrm{SrCO}_{3}$ are 1.291(13) and 1.31(2) $\AA$ and identical within errors with data from Ono et al. (2005a) for $\mathrm{CaCO}_{3}$.

\section{Conclusions}

Powder X-ray diffraction in combination with single-crystal $\mathrm{X}$-ray diffraction was used for the first time to determine 
the high-pressure phase behaviour of $\mathrm{SrCO}_{3}$ up to $49 \mathrm{GPa}$ at ambient temperature. We observed a transformation from strontianite (Pmcn) to post-aragonite $\mathrm{SrCO}_{3}$-II (Pmmn) at around $26 \mathrm{GPa}$, which is in agreement with previous studies that used other techniques, e.g. Raman spectroscopy, to detect a phase transition in $\mathrm{SrCO}_{3}$ (Biedermann et al., 2017a). We present reliable structural information for post-aragonite $\mathrm{SrCO}_{3}$-II, including interatomic distances and anisotropic displacement parameters, and finally resolve the discussion about the correct space group setting of the post-aragonite phase in $\mathrm{SrCO}_{3}$. Our results further confirm a bulk modulus of 62.7(6) $\mathrm{GPa}$ for strontianite $\left(\mathrm{SrCO}_{3}-\mathrm{I}\right)$ and provide the first experimental data for the equation of state for the high-pressure phase $\mathrm{SrCO}_{3}$-II with $V_{0}=115(1) \AA^{3}, K_{0}=$ 103(10) GPa and $K_{0}^{\prime}=2.3(6)$.

Data availability. The electron microprobe analysis of the sample material and the refinement of the single-crystal X-ray diffraction data on the post-aragonite phase of $\mathrm{SrCO}_{3}$ are included in the Supplement. Further data will be made available upon request for scientific research purposes.

Supplement. The supplement related to this article is available online at: https://doi.org/10.5194/ejm-32-575-2020-supplement.

Author contributions. KA and MW initiated the project. IE and JM processed and contributed powder X-ray diffraction data to this study. NB and EB processed single-crystal X-ray diffraction data and wrote the paper with input from WM and IE. EB refined singlecrystal X-ray diffraction data. KA, GS, WM, KG, AP, and MW participated in X-ray diffraction data acquisition.

Competing interests. The authors declare that they have no conflict of interest.

Acknowledgements. This research was supported by funds from the German Science Foundation (DFG) through the CarboPaT research Unit FOR2125 (AP 262/1-1). We acknowledge the support of the Deutsche Forschungsgemeinschaft (German Research Foundation) and Open-Access Publication Fund of Potsdam University. We thank the Deutsches Elektronen-Synchrotron DESY for provision of beamtime (P02.2, ID11003684) and Hanns-Peter Liermann for additional technical assistance. Careful review from Fernando Cámara and one anonymous reviewer has substantially improved an earlier version of this paper. Nicole Biedermann thanks Monika Koch-Mueller from Geo Research Centre (GFZ) in Potsdam for providing sample material and Thomas Preston from European XFEL for fruitful discussions.

Financial support. This research has been supported by the Deutsche Forschungsgemeinschaft (grant no. AP 262/1-1).
Review statement. This paper was edited by Carmen Sanchez-Valle and reviewed by Fernando Cámara and one anonymous referee.

\section{References}

Angel, R. J., Alvaro, M., and Gonzalez-Platas, J.: EosFit7c and a Fortran module (library) for equation of state calculations, Z. Kristallogr., 229, 405-419, https://doi.org/10.1515/zkri-20131711, 2014.

Antao, S. M. and Hassan, I.: The orthorhombic structure of $\mathrm{CaCO}_{3}, \mathrm{SrCO}_{3}, \mathrm{PbCO}_{3}$ and $\mathrm{BaCO}_{3}$ : Linear structural trends, The Canadian Mineralogist, 47, 1245-1255, https://doi.org/10.3749/canmin.47.5.1245, 2009.

Arapan, S. and Ahuja, R.: High-pressure phase transformations in carbonates, Phys. Rev. B, 82, 184115, https://doi.org/10.1103/physrevb.82.184115, 2010.

Bayarjargal, L., Fruhner, C.-J., Schrodt, N., and Winkler, B.: $\mathrm{CaCO}_{3}$ phase diagram studied with Raman spectroscopy at pressures up to $50 \mathrm{GPa}$ and high temperatures and DFT modeling, Phys. Earth Planet. In., 281, 31-45, https://doi.org/10.1016/j.pepi.2018.05.002, 2018.

Biedermann, N., Speziale, S., Winkler, B., Reichmann, H. J., Koch-Müller, M., and Heide, G.: High-pressure phase behavior of $\mathrm{SrCO}_{3}$ : an experimental and computational Raman scattering study, Phys. Chem. Miner., 44, 335-343, https://doi.org/10.1007/s00269-016-0861-2, 2017a.

Biedermann, N., Winkler, B., Speziale, S., Reichmann, H. J., and Koch-Müller, M.: Single-crystal elasticity of $\mathrm{SrCO}_{3}$ by Brillouin spectroscopy, High Pressure Res., 37, 181-192, https://doi.org/10.1080/08957959.2017.1289193, 2017b.

Birch, F.: Finite Elastic Strain of Cubic Crystals, Phys. Rev., 71, 809-824, https://doi.org/10.1103/physrev.71.809, 1947.

Boulard, E., Goncharov, A. F., Blanchard, M., and Mao, W. L.: Pressure-induced phase transition in $\mathrm{MnCO}_{3}$ and its implications on the deep carbon cycle, J. Geophys. Res.-Sol. Ea., 120, 40694079, https://doi.org/10.1002/2015jb011901, 2015.

Bragg, W. L.: The structure of aragonite, Proceedings of the Royal Society of London. Series A, Containing Papers of a Mathematical and Physical Character, 105, 16-39, https://doi.org/10.1098/rspa.1924.0002, 1924.

Brenker, F. E., Vollmer, C., Vincze, L., Vekemans, B., Szymanski, A., Janssens, K., Szaloki, I., Nasdala, L., Joswig, W., and Kaminsky, F.: Carbonates from the lower part of transition zone or even the lower mantle, Earth Planet. Sci. Lett., 260, 1-9, https://doi.org/10.1016/j.eps1.2007.02.038, 2007.

Dasgupta, R. and Hirschmann, M. M.: The deep carbon cycle and melting in Earth's interior, Earth Planet. Sc. Let., 298, 1-13, https://doi.org/10.1016/j.eps1.2010.06.039, 2010.

Efthimiopoulos, I., Jahn, S., Kuras, A., Schade, U., and KochMüller, M.: Combined high-pressure and high-temperature vibrational studies of dolomite: phase diagram and evidence of a new distorted modification, Phys. Chem. Miner., 44, 465-476, https://doi.org/10.1007/s00269-017-0874-5, 2017.

Efthimiopoulos, I., Müller, J., Winkler, B., Otzen, C., Harms, M., Schade, U., and Koch-Müller, M.: Vibrational response of strontianite at high pressures and high temperatures and construction of P-T phase diagram, Phys. Chem. Miner., 46, 27-35, https://doi.org/10.1007/s00269-018-0984-8, 2019. 
Gavryushkin, P. N., Martirosyan, N. S., Inerbaev, T. M., Popov, Z. I., Rashchenko, S. V., Likhacheva, A. Y., Lobanov, S. S., Goncharov, A. F., Prakapenka, V. B., and Litasov, K. D.: AragoniteII and $\mathrm{CaCO}_{3}$-VII: New High-Pressure, High-Temperature Polymorphs of $\mathrm{CaCO}_{3}$, Cryst. Growth Des., 17, 6291-6296, https://doi.org/10.1021/acs.cgd.7b00977, 2017.

Ghosh, S., Ohtani, E., Litasov, K. D., and Terasaki, H.: Solidus of carbonated peridotite from 10 to $20 \mathrm{GPa}$ and origin of magnesiocarbonatite melt in the Earth's deep mantle, Chem. Geol., 262, 17-28, https://doi.org/10.1016/j.chemgeo.2008.12.030, 2009.

Hammersley, A. P.: FIT2D: a multi-purpose data reduction, analysis and visualization program, J. Appl. Crystallogr., 49, 646-652, https://doi.org/10.1107/s1600576716000455, 2016.

Hemley, R. J., Zha, C. S., Jephcoat, A. P., Mao, H. K., Finger, L. W., and Cox, D. E.: X-ray diffraction and equation of state of solid neon to $110 \mathrm{GPa}$, Phys. Rev. B, 39, 11820-11827, https://doi.org/10.1103/physrevb.39.11820, 1989.

Holl, C. M., Smyth, J. R., Laustsen, H. M. S., Jacobsen, S. D., and Downs, R. T.: Compression of witherite to $8 \mathrm{GPa}$ and the crystal structure of $\mathrm{BaCO}_{3}$ II, Phys. Chem. Miner., 27, 467-473, https://doi.org/10.1007/s002690000087, 2000.

Isshiki, M., Irifune, T., Hirose, K., Ono, S., Ohishi, Y., Watanuki, T., Nishibori, E., Takata, M., and Sakata, M.: Stability of magnesite and its high-pressure form in the lowermost mantle, Nature, 427, 60-63, https://doi.org/10.1038/nature02181, 2004.

Javoy, M.: The major volatile elements of the Earth: Their origin, behavior, and fate, Geophys. Res. Lett., 24, 177-180, https://doi.org/10.1029/96g103931, 1997.

Kalliomäki, M. S. and Meisalo, V. P. J.: Structure determination of the high-pressure phases $\mathrm{RbNO}_{3}-\mathrm{V}, \mathrm{CsNO}_{3}$ III, and $\mathrm{CsNO}_{3}-\mathrm{IV}$, Acta Crystall. B-Stru., 35, 2829-2835, https://doi.org/10.1107/s0567740879010773, 1979.

Kaminsky, F.: Mineralogy of the lower mantle: A review of 'superdeep' mineral inclusions in diamond, Earth-Sci. Rev., 110, $127-$ 147, https://doi.org/10.1016/j.earscirev.2011.10.005, 2012.

Kaminsky, F., Wirth, R., Matsyuk, S., Schreiber, A., and Thomas, R.: Nyerereite and nahcolite inclusions in diamond: evidence for lower-mantle carbonatitic magmas, Mineral. Mag., 73, 797-816, https://doi.org/10.1180/minmag.2009.073.5.797, 2009.

Kelemen, P. B. and Manning, C. E.: Reevaluating carbon fluxes in subduction zones, what goes down, mostly comes up, P. Natl. Acad. Sci. USA, 112, E3997-E4006, https://doi.org/10.1073/pnas.1507889112, 2015.

Korsakov, A. V. and Hermann, J.: Silicate and carbonate melt inclusions associated with diamonds in deeply subducted carbonate rocks, Earth Planet. Sc. Lett., 241, 104-118, https://doi.org/10.1016/j.epsl.2005.10.037, 2006.

Larson, A. C. and Von Dreele, R. B.: General structure analysis system (GSAS) (Report LAUR 86-748), Los Alamos National Laboratory, Los Alamos, New Mexico, 2004.

Li, J., Redfern, S. A., and Giovannelli, D.: Introduction: Deep carbon cycle through five reactions, Am. Mineral., 104, 465-467, https://doi.org/10.2138/am-2019-6833, 2019.

Liermann, H.-P., Konôpková, Z., Morgenroth, W., Glazyrin, K., Bednarčik, J., McBride, E. E., Petitgirard, S., Delitz, J. T., Wendt, M., Bican, Y., Ehnes, A., Schwark, I., Rothkirch, A., Tischer, M., Heuer, J., Schulte-Schrepping, H., Kracht, T., and Franz, H.: The Extreme Conditions Beamline P02.2 and the Extreme Conditions
Science Infrastructure at PETRA III, J. Synchrotron Radiat., 22, 908-924, https://doi.org/10.1107/s1600577515005937, 2015.

Lin, C.-C. and Liu, L.-G.: Post-aragonite phase transitions in strontianite and cerussite: A high-pressure Raman spectroscopic study, J. Phys. Chem. Solids, 58, 977-987, https://doi.org/10.1016/s0022-3697(96)00201-6, 1997.

Litasov, K.: Physicochemical conditions for melting in the Earth's mantle containing a C-O-H fluid (from experimental data), Russ. Geol. Geophys., 52, 475-492, https://doi.org/10.1016/j.rgg.2011.04.001, 2011.

Litasov, K. D., Shatskiy, A., Ohtani, E., and Yaxley, G. M.: Solidus of alkaline carbonatite in the deep mantle, Geology, 41, 79-82, https://doi.org/10.1130/g33488.1, 2013.

Mao, H. K. and Hemley, R. J. M. A. L.: Diamond-cell research with synchrotron radiation, Advances in High Pressure Research, 29, 12-20, 1997.

Mao, H. K., Xu, J., and Bell, P. M.: Calibration of the ruby pressure gauge to $800 \mathrm{kbar}$ under quasi-hydrostatic conditions, J. Geophys. Res., 91, 4673, https://doi.org/10.1029/jb091ib05p04673, 1986.

Martinez, I., Zhang, J., and Reeder, R. J.: In situ X-ray diffraction of aragonite and dolomite at high pressure and high temperature; evidence for dolomite breakdown to aragonite and magnesite, Am. Mineral., 81, 611-624, https://doi.org/10.2138/am-1996-5608, 1996.

McCammon, C., Bureau, H., Cleaves, J. H., Cottrell, E., Dorfman, S. M., Kellogg, L. H., Li, J., Mikhail, S., Moussallam, Y., Sanloup, C., Thomson, A. R., and Brovarone, A. V.: Deep Earth carbon reactions through time and space, Am. Mineral., 105, 22-27, https://doi.org/10.2138/am-2020-6888ccby, 2020.

Merlini, M., Crichton, W. A., Hanfland, M., Gemmi, M., Muller, H., Kupenko, I., and Dubrovinsky, L.: Structures of dolomite at ultrahigh pressure and their influence on the deep carbon cycle, P. Natl. Acad. Sci. USA, 109, 13509-13514, https://doi.org/10.1073/pnas.1201336109, 2012a.

Merlini, M., Hanfland, M., and Crichton, W.: $\mathrm{CaCO}_{3}$-III and $\mathrm{CaCO}_{3}$-VI, high-pressure polymorphs of calcite: Possible host structures for carbon in the Earth's mantle, Earth Planet. Sc. Lett., 333-334, 265-271, https://doi.org/10.1016/j.epsl.2012.04.036, 2012b.

Nguyen-Thanh, T., Bosak, A., Bauer, J. D., Luchitskaia, R., Refson, K., Milman, V., and Winkler, B.: Lattice dynamics and elasticity of $\mathrm{SrCO}_{3}$, J. Appl. Crystallogr., 49, 1982-1990, https://doi.org/10.1107/s1600576716014205, 2016.

Oganov, A. R., Glass, C. W., and Ono, S.: High-pressure phases of $\mathrm{CaCO}_{3}$ : Crystal structure prediction and experiment, Earth Planet. Sc. Lett., 241, 95-103, https://doi.org/10.1016/j.epsl.2005.10.014, 2006.

Ono, S.: New high-pressure phases in $\mathrm{BaCO}_{3}$, Phys. Chem. Miner., 34, 215-221, https://doi.org/10.1007/s00269-006-0140-8, 2007.

Ono, S., Kikegawa, T., Oshishi, Y., and Tsuchiya, J.: Post-aragonite phase transformation in $\mathrm{CaCO}_{3}$ at $40 \mathrm{GPa}$, Am. Mineral., 90, 667-671, https://doi.org/10.2138/am.2005.1610, 2005a.

Ono, S., Shirasaka, M., Kikegawa, T., and Ohishi, Y.: A new highpressure phase of strontium carbonate, Phys. Chem. Miner., 32, 8-12, https://doi.org/10.1007/s00269-004-0428-5, 2005b.

Ono, S., Brodholt, J. P., and Price, G. D.: Phase transitions of $\mathrm{BaCO}_{3}$ at high pressures, Mineral. Mag., 72, 659-665, https://doi.org/10.1180/minmag.2008.072.2.659, 2008. 
Rigaku Oxford Diffraction: CrysAlis PRO software system, Version 1.171.40.57a, Rigaku Oxford Diffraction, Oxford, UK, 2019.

Ringwood, A.: Composition and petrology of the Earth's mantle, McGraw-Hill, New York, 618, 1975.

Santillán, J. and Williams, Q.: A high pressure X-ray diffraction study of aragonite and the post-aragonite phase transition in $\mathrm{CaCO}_{3}$, Am. Mineral., 89, 1348-1352, https://doi.org/10.2138/am-2004-8-925, 2004.

Santos, S. S., Marcondes, M. L., Justo, J. F., and Assali, L. V.: Stability of calcium and magnesium carbonates at Earth's lower mantle thermodynamic conditions, Earth Planet. Sc. Lett., 506, 1-7, https://doi.org/10.1016/j.epsl.2018.10.030, 2019.

Shannon, R.: Revised Effective Ionic Radii and Systematic Studies of Interatomic Distances in Halides and Chaleogenides, Acta Crystall. A-Crys., 32, 751-767, https://doi.org/10.1107/S0567739476001551, 1976.

Shcheka, S. S., Wiedenbeck, M., Frost, D. J., and Keppler, H.: Carbon solubility in mantle minerals, Earth Planet. Sc. Lett., 245, 730-742, https://doi.org/10.1016/j.epsl.2006.03.036, 2006.

Sheldrick, G. M.: SHELXT - Integrated space-group and crystal-structure determination, Acta Crystallogr. A, 71, 3-8, https://doi.org/10.1107/s2053273314026370, 2015.

Sobolev, N. V., Yefimova, E. S., Channer, D. M. D., Anderson, P. F. N., and Barron, K. M.: Unusual upper mantle beneath Guaniamo, Guyana shield, Venezuela: Evidence from diamond inclusions, Geology, 26, 971-974, 1998.

Solomatova, N. V. and Asimow, P. D.: Ab initio study of the structure and stability of $\mathrm{CaMg}\left(\mathrm{CO}_{3}\right)_{2}$ at high pressure, Am. Mineral., 102, 210-215, https://doi.org/10.2138/am-2017-5830, 2017.
Thomson, A., Kohn, S., Bulanova, G., Smith, C., Araujo, D., and Walter, M.: Trace element composition of silicate inclusions in sub-lithospheric diamonds from the Juina-5 kimberlite: Evidence for diamond growth from slab melts, Lithos, 265, 108124, https://doi.org/10.1016/j.lithos.2016.08.035, 2016.

Townsend, J. P., Chang, Y.-Y., Lou, X., Merino, M., Kirklin, S. J., Doak, J. W., Issa, A., Wolverton, C., Tkachev, S. N., Dera, P., and Jacobsen, S. D.: Stability and equation of state of post-aragonite $\mathrm{BaCO}_{3}$, Phys. Chem. Miner., 40, 447-453, https://doi.org/10.1007/s00269-013-0582-8, 2013.

Villiers, J. P. R. D.: Crystal structures of aragonite, strontianite and witherite, Am. Mineral., 56, 758-767, 1971.

Wang, M., Liu, Q., Nie, S., Li, B., Wu, Y., Gao, J., Wei, X., and $\mathrm{Wu}, \mathrm{X}$.: High-pressure phase transitions and compressibilities of aragonite-structure carbonates: $\mathrm{SrCO}_{3}$ and $\mathrm{BaCO}_{3}$, Phys. Chem. Miner., 42, 517-527, https://doi.org/10.1007/s00269-015-07402, 2015.

Wirth, R., Kaminsky, F., Matsyuk, S., and Schreiber, A.: Unusual micro- and nano-inclusions in diamonds from the Juina Area, Brazil, Earth Planet. Sc. Lett., 286, 292-303, https://doi.org/10.1016/j.epsl.2009.06.043, 2009.

Zhang, Y.-F., Liu, J., Qin, Z.-X., Lin, C.-L., Xiong, L., Li, R., and Bai, L.-G.: A high-pressure study of $\mathrm{PbCO}_{3}$ by XRD and Raman spectroscopy, Chinese Physics C, 37, 038001, https://doi.org/10.1088/1674-1137/37/3/038001, 2013.

Zucchini, A., Prencipe, M., Belmonte, D., and Comodi, P.: $\mathrm{Ab}$ initio study of the dolomite to dolomite-II highpressure phase transition, Eur. J. Mineral., 29, 227-238, https://doi.org/10.1127/ejm/2017/0029-2608, 2017. 